\title{
Evaluation of Mobile Apps Effectiveness in Children with Autism Social Training via Digital Social Stories
}

\author{
https://doi.org/10.3991/ijim.v14i03.10281 \\ Agathi Stathopoulou'(『) \\ N.C.S.R. "Demokritos", Agia Paraskevi, Athens, Greece \\ agathi.stathopouloulyahoo.com \\ Dionisis Loukeris, Zoe Karabatzaki \\ Ministry of Education, Athens, Greece \\ Evangelia Politi \\ Master in Special Education, Athens, Greece \\ Yolanda Salapata, Athanasios Drigas \\ N.C.S.R. "Demokritos", Athens, Greece
}

\begin{abstract}
The emerging and widespread use of technology to support students with autism is evident by the growing number of studies investigating the use of technology-based interventions, including mobile technologies. Most of the recent research concerning the use of mobile apps has been focused on social story effectiveness. This study tried to evaluate the effectiveness of digital social stories on children with autism social skills acquisition. Three students with high functioning autism were watching for one- year social scenarios through an Android tablet solving social interaction problems. According to the results, appropriate social behaviors in children with autism could be integrated for a long time.
\end{abstract}

Keywords-Mobile apps, autism, social skills, social stories

\section{Introduction}

The launch of digital learning into teaching and training has introduced new possibilities and challenges for students with autism. Digital learning focuses on a new and more effective orientation in special education. This technology is ubiquitous, wireless, highly portable and endowed with multimedia capabilities, providing thus a new dimension to every skill teaching [1]. Especially, new technologies and interactive tools could be very effective in supporting students with educational dysfunction such as children with autism through cognitive, social and emotional methods [2].

During the last decade, the use of mobile learning technologies in autistic children's education has been impressively increased being useful for several purposes, such as the educational environment. The technology devices have attracted the interest of 
many researchers mainly due to their versatile gaming capabilities [3]. Each new version of these devices brings innovative features making them more convenient and affordable. Moreover, the students' academic and social life has been made easier through new apps new applications that have been continually available. These benefits have prompted educators and parents to utilize these devices to promote teaching and learning. There is great potential in using mobile devices to enhance traditional learning by presenting the words and acts more interactively and effectively. As a result, the pupils are more autonomous to learn out of any time or place frame and the whole learning occurs through radical and innovative methods.

As a result, is essential to help students with autism to achieve greater autonomy so that they could independently perform day-to-day activities [5]. Digital aid and especially mobile apps enable them to live independently. So, this should be the purpose of an educational environment: activities should encourage students to develop social skills and acquire social knowledge that will be useful during their entire life. Therefore, the design of this kind of applications which offer usability (designing easy-to-use applications, ensuring that users can interact with them and understanding both the tasks to be accomplished, and also the response of the system), flexibility (allowing educators to customize and adapt application contents according to both user and educational contexts) and mobility (mobile devices have become a very useful support in constructing learning applications because they provide the opportunity to use them in several places within the school) may be really useful for students with many difficulties such as children with autism[6].

Children with autism are a special group of users where a special application design is needed. Children with autism have limitations in the perception of the normal world, being deprived of social relationships; have difficulties in concentrating on individual stimulus and lack organizational skills [7]. Typically, these children have also special educational needs, and standard training methods and systems need to be adapted accordingly to their difficulties. Therefore, mobile apps are some of the preferred and affordable technologies for these children. Although it is a relatively new direction in computer technology, the large use of modern mobile technologies, such as tablets and smartphones, in the daily lives of people with autism [8], they quickly learn to use them for fun, communication, and training. Mobile applications are very helpful for children with autism since they can be used as a communication tool in everyday activities. Its' features include flexible multimedia content and storage, portability, mobility, and affordability. The touch screen interface makes more appealing and simpler to use, particularly for those who have weak motor skills. Last but not least, practical communication solutions are provided to children with autism ensuring effective interaction not only in school but also in another social context. The flexibility and the advanced capabilities of mobile technology bring new opportunities for further research in the area of computer-based intervention for children with autism. Several anecdotal reports give an early indication of the immense possibilities of how these devices could play a significant role in enhancing the quality of life for children with autism and their families [9]. 


\section{$2 \quad$ Autism and Social Deficit}

Difficulties in social adaptation and conciliation with the environment are basic characteristics of autism. An additional difficulty of an autistic child could be the undesirable behavior using to communicate and express their needs [10]. Autism is defined as a diffuse developmental disorder consisting of one or more difficulties, including deficit in various areas such as communication skills and social interaction [7] The precise definition of social skills of children with autism is difficult to be defined due to the different types of functionality. The "Trinity of Wing Disorders" is the three main features of the disorder that identify people with autism. Specifically, the deficit in mutual social interaction reduced skills in verbal and non-verbal communication and imagination and a small variety of activities and interests [11]. Notably, the characteristics of the disorder related to social behavior and communication are the weakness of social responsiveness and the lack of empathy. People with autism are experiencing a deficit in the ability to perceive the feelings and thoughts of others, so they are not able to understand and analyze how people react around them and interact with their environment effectively. Often students with autism show indifference to the social environment and do not search for communication in their social context [12]. It is perceived by research findings that children with autism have difficulties in learning social rules, social conventions and behaviors in contrast to their peers. These difficulties can cause problems in social interaction, social participation, learning, and mental health. Problems in these areas will lead to problems such as high levels of anxiety and inappropriate or aggressive behavior [13].

Various educational interventions and methods have been designed aiming to develop the social skills of students with autism. The implementation of the appropriate method is determined by the needs and abilities of each student [14].

\section{Social Stories}

Social Stories for children with autism are structured in a specific way in which is objectively described the person, the ability, the factor the social environment. It is crucial to be understood the way that the child with autism understands the social circumstance in such a social story. The majority of social stories are written by teachers and parents and their purpose is to perform relevant information such as "where" and "when, "who takes part", "what exactly is happening", and "why" [15]. Social stories describe in detail and with clarity social messages of a particular situation from the point of view of the child with autism and suggest appropriate responses aiming to support the child to improve his behavior. A social story is the simplified description of a particular situation experienced or implicated by the child with autism, written through the child's eye, deriving from its experience [16]. It is considered that a social story, provides information, appropriate support, guidance, and reward to the person with autism and his / her environment. It is also believed that because of social stories may unwanted behaviors be reduced [17]. 
The aim of social stories is the student with autism to develop appropriate behaviors. The teaching of social understanding and the pursuit of the description of each social circumstance must be achieved without directing and forcing the individual to adopt specific behavior [18]. The structure and content of social stories are inherent in the skills of students with autism as they are brief and comprehensive, optical and illustrated, permanent and adjustable for each child and any context [19]. The support provided by social stories is directly related to the way they are written and their purpose in each different case. Generally, social stories aim to provide the necessary information by visualizing, do not rely on interpersonal contact, provide incentives to express the desired behavior, give confirmation, and offer positive feedback to a student with autism [20].

Undoubtedly, the main purpose of a social story is the teaching of social rules and norms. For this reason, the creator of each social story must provide accurate information and descriptions of the situations described in the story. The second stage of writing is the collection of the necessary information coming from the analysis of the circumstances which need to be described and the context in which the story takes place. It is important that whoever wants to create a social story, through observation and recording, need to be aware of the circumstances and the general context in which the situation takes place. It is considered important to determine the place, the time, the causes, the people taking part, the reactions of the person for whom the story is created as well as to describe the desired behavior which is expected by the individual [21]. Social Stories have been designed according to a specific predetermined structure. They usually consist of two to five descriptive proposals, perspectives and/or directional propositions using direct, literal and accurate vocabulary [22]. It is important to mention that social stories have been criticized by the scientific community due to their shortterm maintenance of the results [23] and because the taught behavior cannot be generalized in different environments and at different times [24].

Summarizing, each social story is created exclusively for a particular student and describes a difficult or anxious situation for the child. Before designing and composing each story, the careful assessment of the circumstances, the occasions and the causes of the anxiety of the person have been completed. The evaluation also helps to ensure that the story is adapted to the linguistic and knowledge level of the student. It is important to be presented in the first person with the verbs in the present or future tenses [25]. During the last decade, a new learning approach through social stories emerged in international literature. Digital social stories combine social stories with the effectiveness of information and communication technologies (ICTs) and have introduced new paths to help students with autism and especially in social skills [20]. 


\section{The Methodology of Our Research}

\subsection{Purpose of our research}

Our study aimed to investigate whether digital social stories enable and encourage children with autism appropriate social behaviors in situations in which they are facing management difficulties.

\subsection{Main research question}

The main research question that we were concerned about was the evaluation of the effectiveness of the use of digital social stories and, in particular, the generalization of the desirable behaviors of students with autism.

\subsection{Data collection}

An intervention was developed based on an application for Android tablets that presents interactive social scenarios with friends. An educational evaluation tool was created for the assessment of social skills based on TEACCH's method (Treatment and Education of Autism and related Children Communication Handicapped) [26],[27],[28].

\subsection{Participants}

Participants were selected from 30 high functioning autistic children attending 10 neighboring schools in the Athens area. Because this study concerned the implementation of a specific intervention program, the final sample had to meet certain criteria as to have above overage I.Q and can handle an app on the tablet. Therefore, in the final group of participants, three students were selected boys aged 12,13 and 14 years old.

\subsection{Procedure}

Each participant was given an Android tablet with interactive social scenarios through which they could overcome their social difficulties. Children with autism used the application from September of 2017 to June of 2018. The educational assessment tool for children with autism in social skills was granted by the researchers in three sessions.

\section{$5 \quad$ Results}

Initial assessment - September 2017

Child 1 - 12 years old

Graph 1. 
Appropriate social interaction with friends

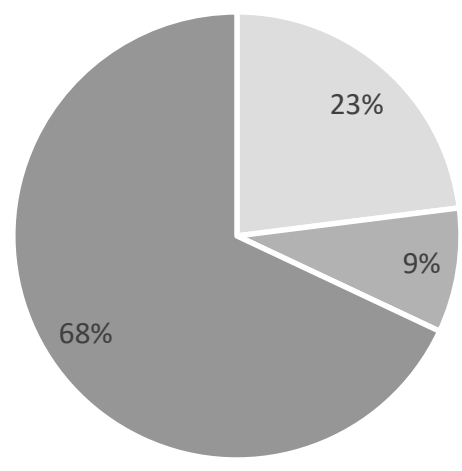

= alone $\quad$ can not alone $\quad$ adult support

Child 2 - 13 years old

Graph 2

Appropriate social interaction with friends

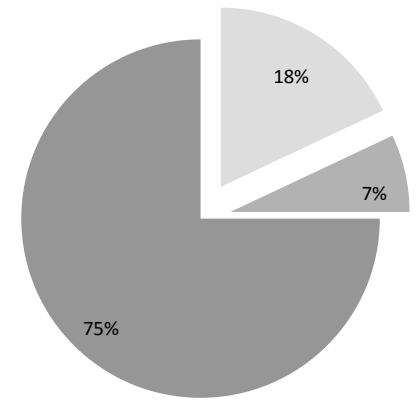

alone can not alone adult support

Child 3 - 14 years old

Graph 3 
Appropriate social interaction with friends

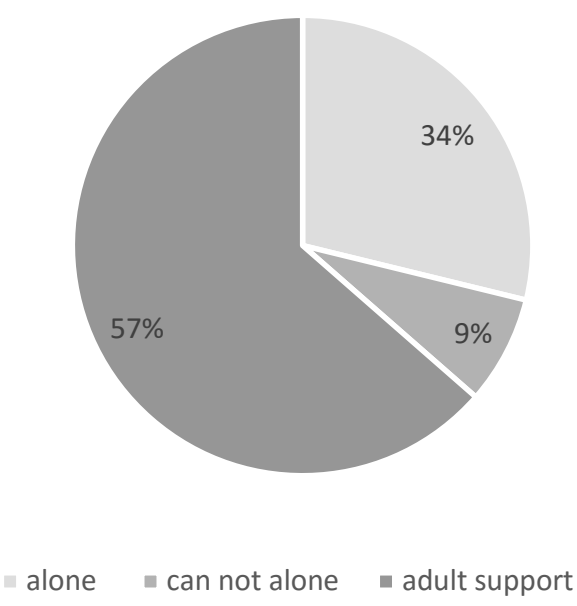

Intermediate assessment - January 2018

Child 1 - 12 years old

Graph 4

Appropriate social interaction with friends

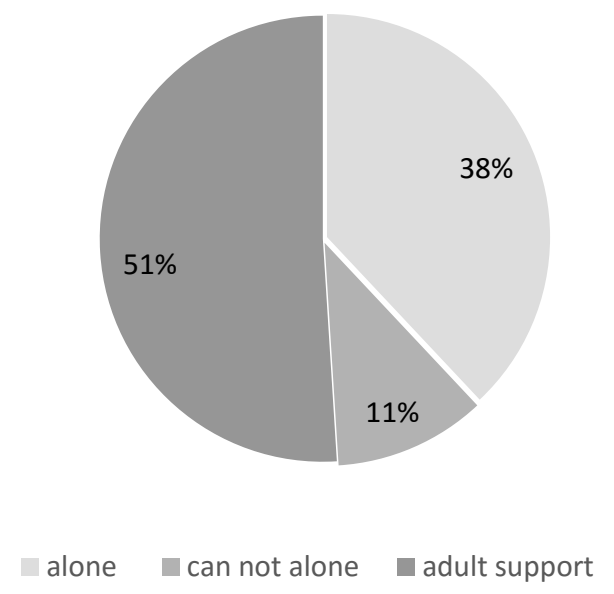

Child 2 - 13 years old

Graph 5 
Appropriate social interaction with friends

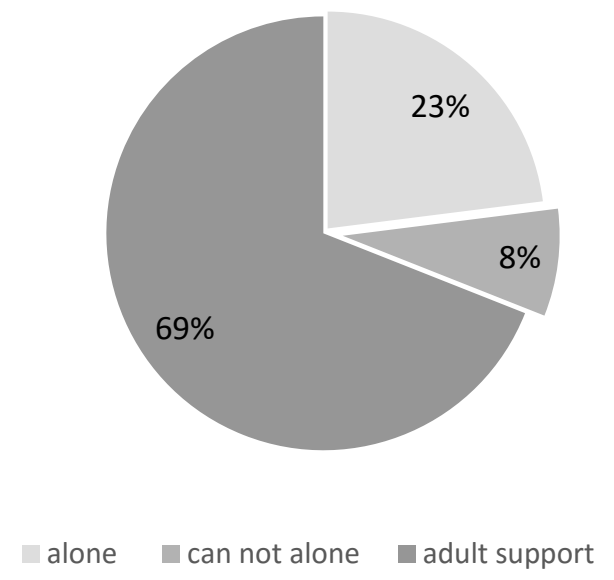

Child 3 - 14 years old

Graph 6

Appropriate social interaction with friends

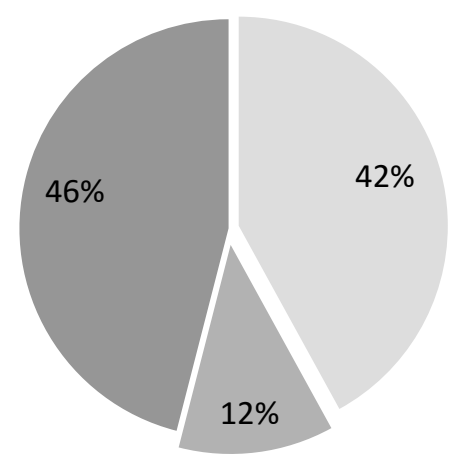

alone $\quad$ can not alone $\quad$ adult support

Final assessment - June 2018

Child 1 - 12 years old

Graph 7 


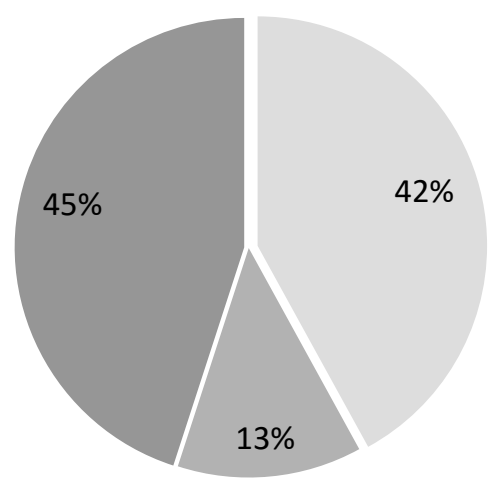

$$
\text { alone can not alone } \quad \text { adult support }
$$

\section{Child 2 - 13 years old}

Graph 8

Appropriate social interaction with friends

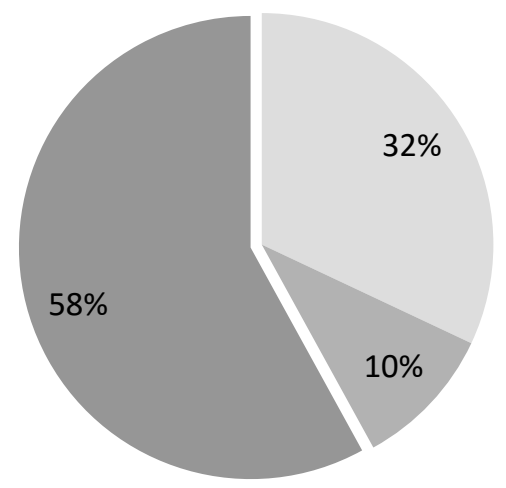

alone $\quad$ can not alone $\quad$ adult support

\section{Child 3 - 14 years old}

Graph 9 


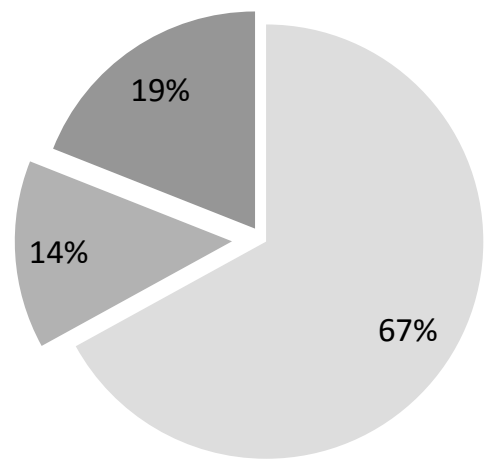

alone $\quad$ can not alone $\quad$ adult support

\section{Conclusion-Discussion}

The purpose of the current research was to evaluate the effects of digital social stories via an Android tablet, on the social skills acqui-sition of students with autism and especially in their relationships with friends. As it is mentioned above, technology can help students with autism overcome social difficulties. It is notable that ICT can expand opportunities for social interactions. The enthusiasm surrounding the use of new technologies (smartphones and tablets) to support children with autism may be due to the affinity of these children exhibit for such devices [29]. Well-designed applications offer consistent and clearly defined tasks and visually cued instructions instead of complicated verbal instructions, which may cause several misunderstandings [30]. Social scenarios on an application for Android tablets is an instructional technique that involves a student watching a video of a model (e.g., a peer or adult) engaging in specific behaviors or skills, with the student later performing the same skill. [31]. In addition, recent research has identified that students with autism only demonstrate signs can't skill acquisition not only when these are taught using mobile technologies, but also if instructions are given through such devices [32]

Social stories have the potential to apply to a range of social contexts, like managing a difficult situation or acquiring a new skill. However, there is a limited number of studies that provide generalized behavioral data as social stories are not intended to enhance and develop skills but to reduce the occurrence of undesirable and problematic behaviors [33]. The generalization of ensuring the desirable behavior of a student with autism is the main purpose. The intervention provided needs to occur for a long period 
of time, the application of the method has to be applied in different environments, irrelevant from the treatment sessions, in everyday spontaneous situations. It is obvious that such an intervention could be provided by digital social stories [34].

Mobile applications have been used in many types of research to collect data and apply special educational interventions [35],[36]. In this research social appropriate behavior has been generalized for a long time, September to June using an application for Android tablets. A number of appropriate social behaviors with which children with autism could cope could be noticed. It is notable that in the majority of circumstances. -in the first assessments -high rates of observed appropriate social behaviors were guided by the adults. However, these rates in the final assessments have been limited and the students were found to be capable of reacting properly on their own to several social situations.

The current findings can be used to suggest that social scenarios via an iPad tablet could be an effective option for educators and parents implementing interventions to improve the social performance of students with autism in daily life. Specifically, digital educational intervention allows participants to independently access to technology and prompt themselves through the completion of functional social behaviors without adults' assistance.

The results of our research have been particularly encouraging as it is clear from the three evaluations that the social skills of the children involved improved significantly. Improvement was achieved through the implementation of a specific intervention program that included the social skills education of students through social stories using an application tablet. The children have gradually been able to generalize behaviors and become self-sufficient. That gradual improvement observed over a whole school year has shown that to have more results such application we need to have enough time especially when it comes to children with autism. In conclusion, it has been shown that new technology application is very critical and practical for children with autism as they can be used as a communication and education tool.

\section{$7 \quad$ References}

[1] Melhuis.k\& Falloon G.(2010).Looking to the future:-M-Learning with the I-pad., 1-16.

[2] Edwards, S. Henderson, M. Gronn, D. Scott, A. Mirkhil, M. (2017) "Digital disconnect or digital difference? A socio-ecological perspective on young children's technology use in the home and the early childhood centre," Technology, Pedagogy and Education, vol. 26 (1), pp. 1-17. https://doi.org/10.1080/1475939x.2016.1152291

[3] Litchfield, A. J., Dyson, L. E., Lawrence, E. M., Bachfischer, A. (2007). Directions for mlearning research to enhance active learning. In Annual Conference of the Australasian Society for Computers in Learning in Tertiary Education. Centre for Educational Development, Nanyang Technological University.

[4] Chu, H. C., Hwang, G. J., Tsai, C. C., Tseng, J. C. (2010). A two-tier test approach to developing location-aware mobile learning systems for natural science courses. Computers \& Education, vol 55(4), pp1618-1627. https://doi.org/10.1016/j.compedu.2010.07.004

[5] Chung, L., do Prado Leite, J. C. S. (2009). On non-functional requirements in software engineering. In Conceptual modeling: Foundations and applications (pp. 363-379). Springer, Berlin, Heidelberg. https://doi.org/10.1007/978-3-642-02463-4_19 
[6] Karabatzaki,Z.,Stathopoulou,A.,Drigas,A., et al ( 2018). «Mobile application tools for students in secondary education. An evaluation study». International Journal of Interactive Mobile Technologies (iJIM ) vol 12( 2),pp142-161 https://doi.org/10.3991/ijim.v13i02. $\underline{9896}$

[7] American Psychiatric Association (APA) (2013) Diagnostic and Statistical Manual. 5th ed. Washington, DC: APA.

[8] Kraleva, R.(2017). "ChilDiBu - A mobile application for Bulgarian children with special educational needs," International Journal on Advanced Science, Engineering and Information Technology, vol 7(6),pp 2085-2091. https://doi.org/10.18517/ijaseit.7.6.2922

[9] Vlachou. J., Drigas,A.(2017) "Mobile technology for students \& adults with Autistic Spectrum Disorders (ASD)," International Journal of Interactive Mobile Technologies (iJIM), vol. 11 (1), pp. 4-17 https://doi.org/10.3991/ijim.v11i1.5922

[10] Heward, W. L. (2013). Exceptional children: An introduction to special education (10th ed.). Upper Saddle River, NJ: Pearson Education.

[11] Wing,L.,Gould, J. (1979). Severe impairments of social interaction and associated abnormalities in children: Epidemiology and classification. Journal of autism and developmental disorders, 9(1), pp11-29. https://doi.org/10.1007/bf01531288

[12] Lee, P. F., Thomas, R. E.,Lee, P. A. (2015). Approach to autism spectrum disorder: Using the new DSM-V diagnostic criteria and the CanMEDS-FM framework. Canadian Family Physician, 61(5), 421-424.

[13] Wright, L.A.,McCathren, R. B. (2012). Utilizing social stories to increase prosocial behavior and reduce problem behavior in young children with autism. Child Development Research. https://doi.org/10.1155/2012/357291

[14] Sansosti, F. J., Powell-Smith, K. A., Kincaid, D. (2004). A research synthesis of social story interventions for children with autism spectrum disorders. Focus on autism and other developmental disabilities, 19(4), pp194-204. https://doi.org/10.1177/108835760401900 $\underline{40101}$

[15] Gray, C. (2010). The new Social Story ${ }^{\mathrm{TM}}$ book. Arlington, TX: Future Horizons.

[16] Gray, C. (2000). Writing social stories with Carol Gray: Accompanying workbook to video. Arlington, TX: Future Horizons, Incorporated.

[17] Gray, C. (2002). Friendship on the horizon: Can Social Stories pave the road? Includes Watch, listen, move closer, ease in, a 10 page rip-out insert. Jenison Autism Journal. 14(3), $10-16$.

[18] Kokina, A., Kern, L. (2010). Social Story ${ }^{\mathrm{TM}}$ interventions for students with autism spectrum disorders: A meta-analysis. Journal of Autism and Developmental Disorders, 40 (7), 812826. https://doi.org/10.1007/s10803-009-0931-0

[19] Rhodes, C. (2014). Do Social Stories help to decrease disruptive behaviour in children with autistic pectrum disorders? A review of the published literature. Journal of Intellectual Disabilities, 18(1), 35-50.. https://doi.org/10.1177/1744629514521066

[20] Leaf, J. B., Oppenheim-Leaf, M. L., Leaf, R. B., Taubman, M., McEachin, J., Parker, T., et al. (2015). What is the proof? A methodological review of studies that have utilized social stories. Education and Training in Autism and Developmental Disabilities, 50(2) 127-141. https://doi.org/10.1007/s10803-014-2103-0

[21] Reynhout, G.,Carter, M. (2011). Evaluation of the efficacy of social stories ${ }^{\mathrm{TM}}$ using three single subject metrics. Research in Autism Spectrum Disorders, 5(2), 885-900. https://doi. org/10.1016/j.rasd.2010.10.003

[22] Saad, M. A. E. (2016). The Effectiveness of Social Stories among Children and Adolescents with Autism Spectrum Disorders: Meta-Analysis. International Journal of PsychoEducational Sciences Vol. 5, Issue (2), September-2016, 51. 
[23] Halle, S., Ninness, C., Ninness, S. K., \& Lawson, D. (2016). Teaching social skills to students with autism: A video modeling social stories approach. Behavior and Social Issues, 25, 42-53. https://doi.org/10.5210/bsi.v25i0.6190

[24] Lavelle, T. A., Weinstein, M. C., Newhouse, J. P., Munir, K., Kuhlthau, K. A., \& Prosser, L. A. (2014). Economic burden of childhood autism spectrum disorders. Pediatrics, peds2013. https://doi.org/10.1542/peds.2013-0763

[25] Karal, M. A., Wolfe, P. S. (2018). Social Story Effectiveness on Social Interaction for Students with Autism: A Review of the Literature. Education and Training in Autism and Developmental Disabilities, 53(1), 44-58.

[26] Reichow, B., Wolery, M. (2009). Comprehensive synthesis of early intensive behavioral interventions for young children with autism based on the UCLA Young Autism Project model. Journal of Autism and Developmental Disorders, 39, 23-41. https://doi.org/10. 1007/s10803-008-0596-0

[27] Probst, P., Jung, F., Micheel, J.,Glen, I. (2010). Tertiary-preventive interventions for autism spectrum disorders (ASD) in children and adults: An evaluative synthesis of two TEACCH based outcome studies. Life Span and Disability, 13(2), 129-167.

[28] Welterlin, A., Turner-Brown, L. M., Harris, S., Mesibov, G.,Delmolino, L. (2012). The home TEACCHing program for toddlers with autism. Journal of Autism and Developmental Disorders, 42, 1827-1835. https://doi.org/10.1007/s10803-011-1419-2

[29] Hedges, S.H. Odom, S.l. L,Hume, K. ,Sam, A.(2017) Technology use as a support tool by secondary students with autism Autism, Special Issue Article,1-10, https://doi.org/10. $1177 / 1362361317717976$

[30] Gillespie-Lynch K, Kapp SK, Shane-Simpson C, et al. (2014) Intersections between the autism spectrum and the internet: perceived benefits and preferred functions of computermediated communication. Intellectual and Developmental Disabilities 52(6): 456469. https://doi.org/10.1352/1934-9556-52.6.456

[31] Cihak, D. F., Fahrenkrog, C., Ayres, K. M., Smith, C. (2010). The use of video modeling via a video iPod and a system of least prompts to improve transitional behaviors for students with autism spectrum disorders in the general education classroom. Journal of Positive Behavior Interventions, 12, 103-115. https://doi.org/10.1177/1098300709332346

[32] Shane,H.C.,Albert,P.D.(2008).Electronicscreenmediaforpersonswithautismspectrumdisord ers:Resultsofasurvey. Journal of Autism and Developmental Disorders, 38, 1499-1508.

[33] Qi, C. H., Barton, E. E., Collier, M., Lin, Y. L., \& Montoya, C. (2018). A systematic review of effects of social stories interventions for individuals with autism spectrum disorder. Focus on Autism and Other Developmental Disabilities, 33(1), 25-34. https://doi.org/10.11 77/1088357615613516.

[34] More, C. (2008). Digital stories targeting social skills for children with disabilities: Multidimensional learning. Intervention in School and Clinic, 43(3), 168-177.-31. https://doi.org/10.1177\%2F1053451207312919.

[35] Stathopoulou,A. Karabatzaki,Z., Drigas, A. et al (2018). «Mobile assessment procedures for mental health and literacy skills in education». International Journal of Interactive Mobile Technologies (Ijim) 12 (3),pp21-36. https://doi.org/10.3991/ijim.v12i3.8038

[36] Burton, C., Anderson, D. H., Prater, M. A.,Dyches, T.T. (2013). Video self-modeling on an iPad to teach functional math skills to adolescents with autism and intellectual disability. Focus on Autism and Other Developmental Disabilities, 28(2), 67-77. https://doi.org/10.1177/1088357613478829 


\section{Authors}

Agathi Stathopoulou is Partner of Institute of Informatics \& Telecommunications, Net Media Lab-Brain \& Mind R\&D, N.C.S.R. "DEMOKRITOS", National and Kapodistrian University of Athens. She hold PhD in Stress Disorder \& Adolescent Psychology. She has participated in many educational seminars and conferences as a keynote speaker and as instructor. She has taught at the Department of Special Education of University of Athens and at the Department of Greek Literary of Democritus University of Thrace. She has written one book, and articles in scientific journals(Email: agathi.stathopoulou@yahoo.com).

Dionisis Loukeris is a Counsellor at the Ministry of Education, Research and Religious Affairs in Greece. He holds a PhD in "Environmental Education and Viable Growth" and a Master of Arts in "Theory and Practice of Teaching and Evaluation". He has been an Education Counsellor since 2004, first at the Institute of Educational Policy and then, until today, at the Ministry of Education, Research and Religious Affairs. He has taught at graduate and postgraduate programs at the University of Athens. $\mathrm{He}$ is also a scientific associate at Net Media Lab of N.C.S.R. 'Demokritos'. Writer of lots of books and research articles in Greek and international journals, he has also participated in conferences both in Greece and abroad. (Email: dlookas@ gmail.com).

Zoe Karabatzaki is a School Advisor at the 21st Preschool Educational Region of Athens. She holds a Ph.D. on Educational Sciences (Special Education). She has participated in many educational seminars and conferences as a keynote speaker and as instructor. Furthermore, she has taken part in research programs that were supported by many universities of Greece. She has written two books, chapters in collective volumes, articles in scientific journals and educational notes. She has taught at the Department of Special Education of UTH (University of Thessaly), at the Department of Education and Early Childhood of UOA and the Department of Greek Literary of Democritus University of Thrace. She is also a scientific associate at Net Media Lab, Brain \&amp; Mind R\&amp;D of N.C.S.R. 'Demokritos'. (Email: zkarabatzaki@ gmail.com).

EvangeliaPoliti She is studied in the Faculty of Primary School in the University of Ioannina. She has a Master in Special Education from the University of Thrace and EKEFE Demokritus. She has been working in public primary school as a special educator for the last four years. (E-mail: evageliapoliti@ hotmail.com)

Yolanda Salapata is a Paedodontist and Laser Dentist, Is involved in research for Children with Learning Disabilities and is with N.C.S.R "Demokritos", Institute of Informatics and Telecommunications, Net Media Lab, Agia Paraskevi, 153 10, Athens, Greece (E-mail: paedodontist@gmail.com)

Athanasios Drigas is a director of research at N.C.S.R. Demokritos. He is the Coordinator of Telecoms Lab and founder of Net Media Lab since 1996. From 1985 to 1999 he was the Operational manager of the Greek Academic network. He has been the Coordinator of Several International Projects, in the fields of ICTs, and e-services (elearning, e-psychology, e-government, e-inclusion, e-culture etc). He has published more than 200 articles, 7 books, 25 educational CD-ROMs and several patents. He has been a member of several International committees for the design and coordination of 
Paper-Evaluation of Mobile Apps Effectiveness in Children with Autism Social Training Via Digital...

Network and ICT activities and of international conferences and journals. (E-mail: dr@iit.demokritos.gr).

Article submitted 2019-02-07. Resubmitted 2019-12-10. Final acceptance 2019-12-12. Final version published as submitted by the authors. 